\title{
LUCES EN LA CIUDAD: DICTADURA Y SIMULACRO EN TOMÁS HARRIS*
}

\section{AGDA SEPÚLVEDA ERIZ**}

\section{RESUMEN}

Tomás $\mathrm{H}$ arris, en Zonas de peligro y D iario de navegación, crea la metáfora del baldío para designar a la ciudad dictatorial chilena. Sin embargo, el territorio devastado no es el consecuente en los poemarios sólo del gobierno militar, sino de las políticas de erradicación iniciadas desde la colonización, cuyo efecto ha sido la generación de este espacio habitado por espectros, cuerpos asesinados o desaparecidos. Este texto muestra la coincidencia que $\mathrm{H}$ arris realiza entre la luz moderna y el foco posmoderno para señalar sucesivamente al sujeto que debe erradicarse y la obligada transformación de todo espacio en un baldío.

Palabras claves: Poesía chilena, ciudad, dictadura, Tomás H arris.

\section{ABSTRACT}

In Zonas de peligro and Diario denavegación, Tomás Harris creates the metaphor of the wasteland in order to name the Chilean dictatorial city. Nonetheless, the devastated territory is not just a consequence of the military government, but also of the eradication policies set into motion by the colonization process and whose effect has been the generation of this space inhabited by ghosts, murdered corpses and missing persons. This text shows the agreement worked by Harris between the modern light and the postmodern spotlight, in order to signal successively to the subject that it must be eradicated and to announce the forced transformation of every space into a wasteland.

Keywords: Chilean poetry, city, dictatorship, Tomás Harris.

Recibido: 18.09.2007. Aprobado: 29.11.2007.

* Este texto forma parte del proyecto Fondecyt N · 10.50.321, "¿N eovanguardia, modernidad en disolución, posmodernidad? La poesía chilena entre 1973 y 1988", dirigido por el doctor N aín N ómez y del cual quien suscribe es la coinvestigadora y fue presentado en el XIV Congreso Internacional de Estudios Literarios, Universidad deTarapacá, agosto, 2006

** Profesora dela Facultad deLetras delaP.U niversidad C atólica deChile. E-mail: msepulvu@uc.cl 


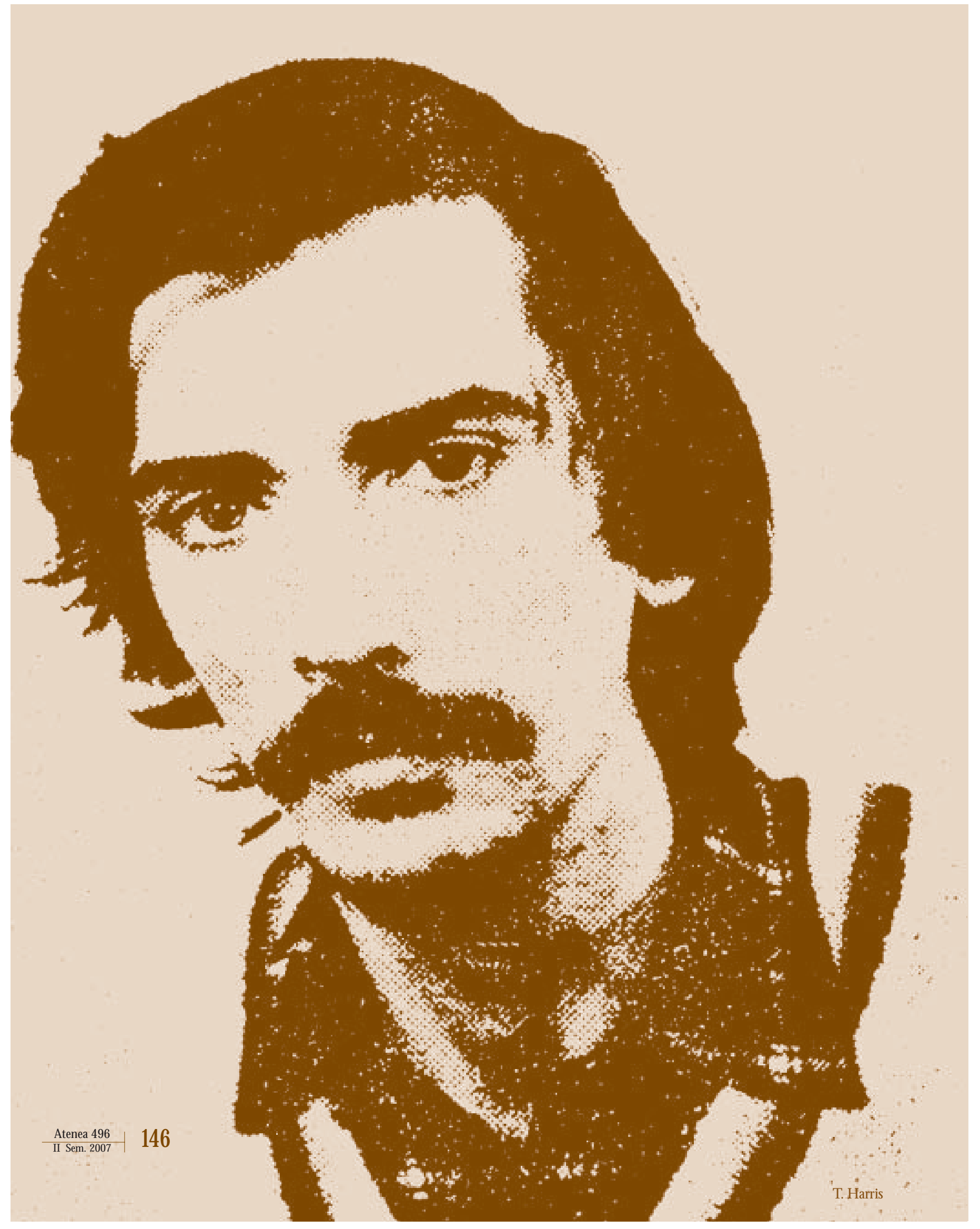


A CIUD AD es un espacio físico y un espacio simbólico. C omo lugar físico se recorre, se marca, se convierte en 'territorio'1; como espacio simbólico, la ciudad es representada iconográficamente (fotografías, postales e imágenes televisivas, entre otros) y verbalmente (periódicos, emisiones radiales, libros de historia y otros). La urbe es también una representación literaria: varios son los poetas que escribieron sobre las ciudades bajo la dictadura chilena, Enrique Lihn con Paseo Ahumada (1983), Eugenia Brito con Vía pública (1984), Carmen Berenguer con H uellas de siglo (1986), entre otros. La mayoría de estos poemarios trabajan sobre las simbolizaciones de Santiago, excepto la escritura de un autor, Tomás H arris, que poetiza Concepción en los libros Zonas de peligro, elaborado entre 1979 y 1982, pero publicado en 1985 en Concepción por Lar, y en D iario denavegación, publicado el mismo año en la misma ciudad, por Editorial Sur². Este trabajo analiza las significaciones que adquiere la metáfora del baldío para designar a la ciudad dictatorial chilena en los dos poemarios señalados.

\section{LA CIUDAD BALDIO}

Zonas de peligro elabora un discurso poético sobre la forma de habitar el espacio público en una "ciudad sudamericana al sur de las estrellas", caracterizándola por el temor que convierte la urbe en un baldío espectral. El hablante en las múltiples posiciones que adquiere en este libro, según se sitúe en la calle Prat, O rompello o el H otel King, ve los muros de la ciudad, repara en su 'encalado', escucha el grito de los asesinados: construye una ciudad aterradora. La repetición del enunciado "muro encalado" constituye una isotopía ${ }^{3}$ del poemario, la cual tiene por matriz "El gato negro" de Poe, donde el cadáver de una mujer es descubierto bajo la cal con que su asesino la emparedó. En ese cuento, los muertos emparedados comunican a través de los relieves o sonidos que emiten las murallas y este decir de los muros tortura al narrador de Poe quien, al explicar el objetivo de su relato, dice: "M i propósito inmediato consiste en poner de manifiesto, simple, sucintamente y sin comentarios, una serie de episodios domésticos. Las consecuencias de esos episodios me han aterrorizado, me han torturado y, por fin, me han disminuido" (Poe 1984: 61). Los mismos sentimientos de terror y de menoscabo del yo experimenta el sujeto poético. La

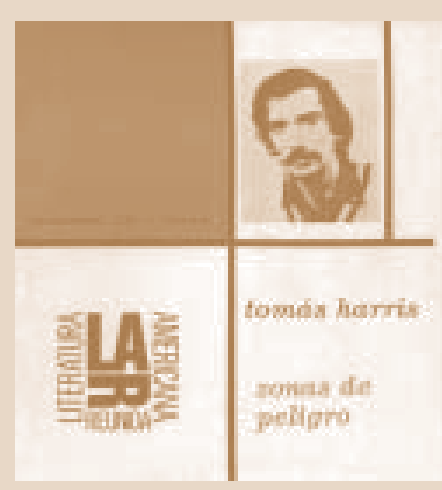

${ }^{1}$ El concepto de 'territorio' fue desarrollado por los etólogos para describir de la conducta animal en relación a su hábitat (cfr. Silva 2000:47).

${ }^{2}$ La Editorial Sur pertenecía a Juan Pablo Riveros, poeta, y la editorial Lar a 0 mar Lara, también poeta. D ado que estas dos editoriales se ubicaron en Concepción, se podría plantear que un fuerte movimiento intelectual operó en la zona, sin el financiamiento del Estado y a contrapelo de la dictadura.

${ }^{3}$ Los conceptos de "isotopías" provienen de Rastier (Rastier, Francois. "Sistemática delas isotopías". Ensayos desemiótica poética. Comp. A.J. Greimas. Barcelona: Planeta, 1976, pp.107-140) y el "matriz" de Riffaterre (Riffaterre, M ichel. Semi oti cs of Poetry. London: Indiana U niversity Press, 1978). 
mirada que él crea de esta ciudad espectral está ligada a lo ominoso, es decir, según Freud (1967), se trataría de aquella variedad de lo terrorífico que se remonta a lo consabido de antiguo, a lo familiar o conocido desde hace largo tiempo. Siguiendo este concepto, puedo inferir queel inconsciente del hablante reconoce los crímenes que el consciente niega, planteándose este doble movimiento de aceptación/negación para el modo de habitar la ciudad de la dictadura.

La ciudad espectral aparece tras una herida no cerrada, dicha en el poemario a través de la metáfora 'faja'. C oncepción se vuelve metonimia del país al ser descrito bajo la tópica de "faja", a saber, "C hile, larga y angosta faja de tierra", configuración simbólica que cambia de dirección en los versos de H arris, "así como largas y angostas fajas de barro / así como largasy angostas fajas de noche / Así como largas y angostas fajas de musgo rojo" (29). La resemantización de la palabra 'faja' adquiere ahora el sentido de 'estar fajado', vale decir estar envuelto 0 atado, herido y amordazado. Ya no es una faja 'de tierra' como nos diseña la tópica sino faja 'de barro', 'de noche' y 'de musgo rojo'; cambios que diseñan el circuito semántico del terror.

La transformación de la ciudad se materializa en la creación de un nuevo espacio, el baldío. El país entero y la ciudad de Concepción se tornan un baldío donde habitan los cuerpos tachados por un sistema omnipresente. El inicio del peladero está marcado por una separación visible, cerro o muro, a partir de la cual el sujeto y el espacio se integran, ambos son un baldío un lugar devastado. El hablante sitúa en una cadena sintagmática cuerpo, bal dío y muro, "en los muros en los / cuerpos huecos rojos / huecos por donde se transparentaba este bal dío" (50), incluso reproduce con los espacios en blanco el peladero gestado. El sujeto que habita el descampado es un cuerpo fantasmal y dehecho posee un orificio de bala o hueco rojo aunque camina. Ya T.S. Eliot había realizado esta asociación entre bal dío, ciudad irreal y muertos en su poemario La tierra baldía (1922), especialmente en la primera parte, "El entierro de los muertos", donde un marinero que vaga por Londres observa las calles pobladas de espectros: "Ciudad irreal, / bajo la niebla parda de un amanecer deinvierno, / una multitud fluía por el Puente de Londres, tanta, / no creí que la muerte hubiera deshecho a tantos. / Se exhalaban suspiros, breves y poco frecuentes, / y cada cual Ilevaba los ojos fijos ante los pies" (Eliot 1989: 78). La situación del hablante de $\mathrm{H}$ arris es similar. Si Londres para Eliot ha sido aniquilada por el dinero, léase el capitalismo y su moral burguesa, para H arris, C oncepción ha sido devastada desde el acto de fundación o bautismo verbal, de ahí que el asolamiento del territorio se dobla en el lenguaje del poema, donde los cortes intrapalabras remiten a las incisiones que experimenta el cuerpo al momento de ser maltratado.

El baldío está habitado por mendigos, prostitutas y travestis, vale decir, cuerpos rechazados y a la vez producidos por el sistema que los arroja a ese lugar, y por ello es un espacio posible en todo el continente: "Esta es la luna, / 
viene desde Lima, / va hacia N ueva York; / brilló sobre un millón de mendigos en el Perú; / brillará sobre diez millones de mendigos en N ueva York, / brilla sobre miles de mendigos en Concepción" (48). El baldío es entonces una cárcel donde están recluidos los apestados, "el / baldío de 0 rompello te inventa una cárcel oculta al otro extremo de la Concep- / ción" (49). Una de las pare des de esta cárcel es 0 rompello, calle donde se ejercía la prostitución en Concepción y las otras murallas son el cerro La C ruz y el río Bío-Bío, límites que crean la ciudad como camino hacia la muerte.

Tal como el encuentro amoroso, erótico, no existe en la ciudad espectral de T.S.E, en $\mathrm{H}$ arris tampoco se presenta el deseo amatorio. La serie de poemas denominados $\mathrm{H}$ otel King I a III dan cuenta de esa relación que recuerda el vínculo de la mecanógrafa con el empleado en el canto III de La tierra baldía: "El momento es ahora propicio, según supone, / la cena ha terminado, ella está aburrida y cansada, / se esfuerza por hacerla entrar en caricias / que, si bien consentidas, no son deseadas" (Eliot 1989: 86). En esta ciudad sitiada, el amor es otro asedio. O scar H ahn (1996) expresa este sentimiento caballeresco en el poema "C astillo dáteme, date", donde la mujer es el espacio que el varón debe tomar. Por el contrario, en $\mathrm{H}$ arris no existe esa dinámica de dominar un espacio porque el hablante no tiene fuerzas para apoderarse de los lugares, porque ya no es un héroe caballeresco ni un héroeépico: el amor que ofrece está degradado. El poema parece afirmar que no se puede amar en una ciudad prisión, el doble asedio no funciona, el apoderamiento del espacio al unísono de la conquista de la mujer es un paradigma que se ha quebrado. Este poema se enfrenta a la llíada y lo niega, nadie viajará a rescatar a ninguna $\mathrm{H}$ elena, se da así un diálogo con la tradición que N aín N ómez caracteriza así: "Asistimos a la instauración de un sujeto que incorpora (todas) las tradiciones de la modernidad, pero absorbidas en un texto cuyos discursos disolutorios, corroen paso a paso la ilusión del sujeto moderno" (N ómez 1998: E10). En este caso, los mitos del héroe épico clásico son los que se muestran acabados en esta ciudad donde el habitante herido se mueve entre fantasmas.

La devastación de la ciudad en este poemario no es un hecho del contexto de la publicación del libro, la dictadura, sino un suceso acontecido desde el origen de la fundación de ciudades; por eso el sujeto hablante se sitúa sin problemas de coherencia en diversos tiempos, el presente puede ser el siglo XVI, "hoy el año mil quinientos y veinte fue un / gran tirano" (49) o el pasado puede ser la fecha de inicio de la dictadura, "los muertos de mil novecientos setenta y tres / eran un teatro de sombras exhibidas" (50). El tiempo no avanza, no hay una secuencia histórica para los habitantes del sitio eriazo, pues éste remite tanto al espacio despojado de la conquista como a las políticas de erradicación de la dictadura. El bal dío tiene esa densidad que lo vuelve una posibilidad de significación poética para representar(se) aquellos sujetos que tienen una memoria de ser expulsados de sus territorios.

La ciudad fajada por la dictadura emplea los medios de comunicación como 
envoltura que obliga a los habitantes a sentirse parte de una película. En H arris, la ciudad dictatorial es un falso escenario4, "Ios escasos letreros deneón ocultan su única / identidad: / CAM PO S DE EXT ERM IN IO " (29). Los medios, señalados por un punto de su corriente circulatoria, los letreros de neón, léase la publicidad y el consumo, regulan la circulación de las ideas y del cuerpo. La publicidad, en especial, brinda unidad y homogeneidad a la población, con la exaltación de modelosidentitarios, lo que la constituye en un medio aliado del fascismo, pero también crea un simulacro de realidad donde el sujeto se confunde. $O$ scar $G$ alindo plantea leer estos extravíos de los sentidos como un tópico barroco y "la vida como teatro" (otro tópico barroco) (91), entradas que comparto y a los cuales agrego el antecedente de la dictadura como provocadora de esta confusión realidad/irrealidad. M e apoyo en el poemario que observa a los ciudadanos según los códigos del cine y la televisión; por ello los compara con los prisioneros de otros campos de concentración, "Era Treblinka el lugar de la comedia y no / estábamos en Treblinka" (56). La mediatización del hablante corresponde a un programa de la dictadura, donde la tecnología de las comunicaciones fue un vehículo más de disciplinamiento para instalar el saber o el temor; la importancia dada por el gobierno de Pinochet a la TV fue expresada por el ministro del Trabajo, José Piñera, en 1980: "D e cada siete chilenos, uno tendrá automóvil; de cada cinco, uno tendrá televisor, y de cada siete, uno tendrá teléfono" (EI M ercurio, 28, agosto, 1980). El poemario se hace cargo de esta asociación entre dictadura y sociedad del espectáculo.

El escenario que ilumina al amenazado es construido por un otro que no adquiere presencia en el montaje. Los habitantes de la ciudad viven en un panóptico ${ }^{5}$, donde "no sé si te miran, / pero te miran" (30) que disuelve al sujeto, impidiéndole hablar desde un yo. Este panoptismo lleva a que el sujeto se objetivice como un 'tú' permanentemente observado, acechado por la tecnología del régimen. El relato de los medios dispone lo verosímil y lo incorrecto que proviene de aparatos técnicos; específicamente los noticieros de televisión son los encargados de transmitir verdades creadas y de situar todo gesto de rebelión como incorrecto. Q uisiera recordar un caso emblemático, el de K aren Eitel, la joven universitaria que fue filmada bajo presión y luego el video transmitido por cadena nacional. Sobre estehecho Pedro Lemebel indicó: "Esa sensación de estar frente a un rostro electrificado pudiera ser el argumento para

\footnotetext{
${ }^{4}$ La urbe dictatorial como ciudad producida por los medios es un recurso que han trabajado varios narradores, D iamela Eltit en Lumpérica (1983) y Roberto Bolaño en Estrella distante (1996), entre otros. En este último libro la relación entre medios y dictadura se focaliza en un escritor que registraba en fotos sus ejercicios torturadores: "En algunas de las fotos reconoció a las hermanas $\mathrm{G}$ armendia y a otros desaparecidos. La mayoría eran mujeres. El escenario de fotos casi no variaba de una a otra, por lo que se deduce que es el mismo lugar. Las mujeres parecen maniquíes desmembrados, destrozados" (97).

5 Tomo este concepto del capítulo "EI panoptismo" de Vigilar y castigar (M éxico: Siglo XXI, 1995) de M ichel Foucault. Pp.199-230.
} 
recordar a K aren, para volver a ver, con el mismo escalofrío, su cara tiritando en la pantalla de canal 7, en el noticiario familiar para todo espectador. (Su) rostro elegido para el escarmiento" (90). El poemario asocia las imágenes producidas por esos aparatos a un régimen de terror del ojo: "proyectaban sobrela pared los / aquelarres de Goya" (58). La exhibición del régimen de ciertos cuerpos maltratados da cuenta de una manera de expandir el terror, sin necesariamente tocar una piel.

En el baldío, los cuerpos vulnerables sufren el peso del simulacro. $\mathrm{H}$ arris vuel ve sobre las meretrices de 0 rompello que poetizó G onzalo Rojas, pero ya no son bellas y sensuales, sino un cuerpo espectacularizado, un travesti, Jacqueline: "como en G oldfinger la habían / pintado / de dorado, toda entera" (37). El cuerpo del travesti aparece asesinado, cambiado, decorado y maltratado, siguiendo los códigos de la película James Bond contra Goldfinger (1964). El hablante es un testigo cuyo relato se opone a la narración de los medios, "FEROZ ACTO DE SODOMIA -dirá en los medios" (37), mientras que él asegura que el cuerpo fue golpeado y pintado, "Yo creí que eran aros esos, pero eran / prolongaciones de / suslóbulos" (37). Los poemastitulados "O rompello I", "O rompello II", hasta "O rompello V" tienen por función mostrar al lector la desaparición de los cuerpos más allá de la dictadura, como un suceso de todos los tiempos que queda registrado en los muros dela ciudad, "O rompello data del Pal eolítico Superior de la / ciudad / El amor se ha sedimentado sobre cada geología de / muro" (35). La autoría se centra en los cuerpos de las prostitutas travestis porque la historia de sus cadáveres queda registrada en el muro, pero no en el discurso verbal, "Una de las putas muertas sedimentará en los / adoquines / ya no tendrá historia" (36). N uevamente aquí, el hablante opone historia oficial a historia relatada por los muros de la ciudad.

La historia contenida en los muros de la ciudad es insuficiente, ya que por medio de ella el hablante sólo obtiene retazos. D e ahí el uso de las palabras 'erosionados' o 'barrió' en estos versos, "por estos mismos adoquines ero-/ sionados caminó Luciano Cruz por los 60 / esta misma lluvia y no otra barrió hasta los / desagües las cenizas de Sebastián el inmolado / (... ) el poeta norteamericano Ginsberg leyó en este / miserable rincón sudamericano por los 60" (41). La ciudad penquista es elaborada desde un relato citadino que afectó y modeló la vida de sus habitantes en los años previos y durante la dictadura: Concepción, la ciudad revolucionaria. En ese relato se destacó a L uciano C ruz en su calidad de fundador del M IR (1965); Io acompaña en la sintaxis Sebastián Acevedo, quien se roció con bencina en 1983, en la Plaza de Armas de la ciudad, para pedir que se le informara sobre el paradero de sus dos hijos detenidos por la policía del régimen militar, muriendo a consecuencia de las que maduras. A pesar de estos personajes claves para la historia de una ciudad, el relato no puede construirse y quedan estas escenas como trozos de un algo perdido. El hablante compara esta situación con lo que sucede en un bus,

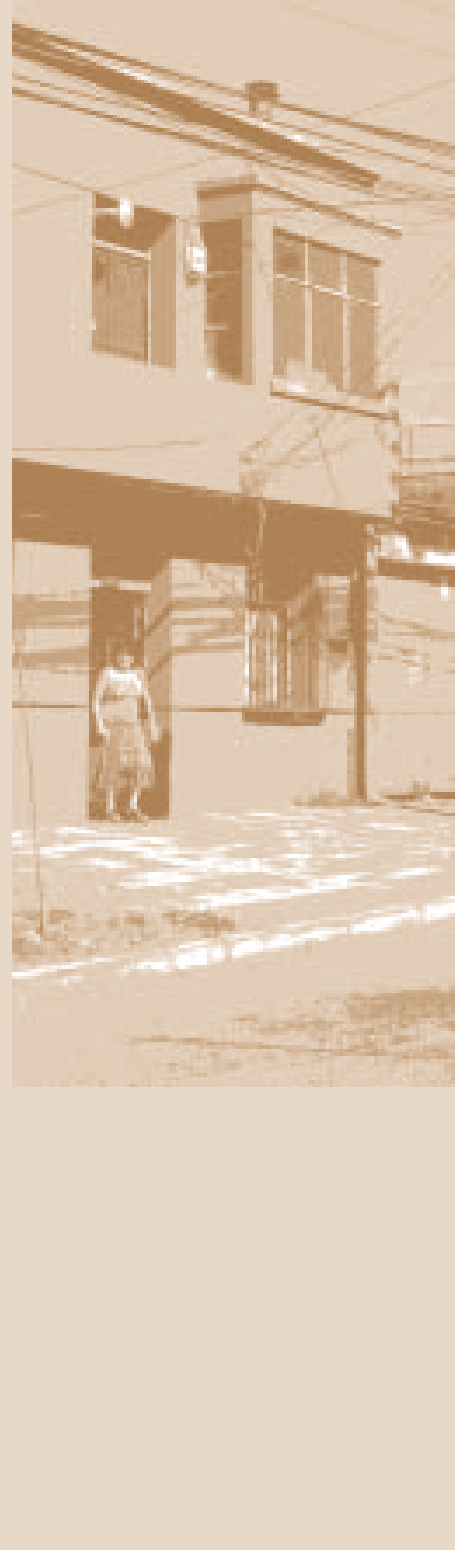

$151 \stackrel{\text { Atenea } 496}{\mid \text { || Sem. } 2007}$ 
“(... ) el fragmento / el mito el par sin cara de tetas pegándose en / la espal da en el pasillo húmedo de la micro" (41). El nuevo ciudadano creado por la dictadura es comparable para $\mathrm{H}$ arris al pasajero que va en un bus, donde observa partes de los cuerpos, pero no ve el todo o mira los paisajes cortados por cada ventana, porque ese viajero ya no sabe el telos. Entonces, la posmodernidad y su retórica del fragmento llegaron con la dictadura que fabricó un simulacro de historia. No hay diferencia entre la situación vivencial del hablante lírico y una descripción de lo posmoderno, "una situación en la que imperan la incertidumbre, el escepticismo, la diseminación, las situaciones derivantes, la discontinuidad, la fragmentación, la crisis" (U rdanibia 1990: 69). La posmodernidad, tal como la dictadura, convierte la historia en un fantasma que se manifiesta por trazos, pero que ya no es total.

\section{LA CIUDAD ESPECTACULARIZADA}

El segundo libro, titulado Diario de navegación, vuelve sobre el tema de la ciudad, creando variadas metáforas para Concepción: Tebas, Argel, Cathay, Tenochtitlán y Cipango, que son a la vez títulos de poemas que componen el libro. Concepción comparte con Tebas el apestamiento, en este caso el chancro, patología bacterial que causa úlceras en la piel de los genitales. La enfermedad se vuelve indicativa del mal gobierno autoritario, cuyas marcas en el poemario están referidas por "Estado de sitio" (112), "todas las noches oyeron I sirenas tanques detonaciones" (99). Para la mente alucinada del hablante, Concepción también es Argel, ciudad que mantiene preso a Cervantes, autor que $\mathrm{H}$ arris usa para una serie de epígrafes que trazan la idea del escritor cautivo. Se observa en el tema de los prisioneros una aliteración del sonido /p/ que funciona reproduciendo la situación de una multitud que cae y cae detenida en este segundo verso, "no puede haber ciudad feliz / repleta de prisioneros y putas por todas partes" (113). Concepción es Cathay (China) en tanto es una ciudad transformada por la imaginación del visitante, sólo que las maravillas atribuidas a $C$ athay se cambian por el horror atribuido a la urbe sureña, específicamente al desmembramiento de los cuerpos ocurrido en la urbey referido a través de las muñecas de Bellmer, artista visual alemán que en la década de 1930 real izó una serie de fotografías sobre maniquíes articulados queél mismo construía, recreando con ello el entorno de sumisión y de docilidad de los cuerpos que fomentaba el nazismo. La mención de estos maniquíes en el poema "C athay" vuelve sobre el gesto de Bellmer, es decir, a representar sobre el cuerpo femenino la violencia política, haciendo una igualdad entre nación y cuerpo femenino.

Concepción es dicha también a través de Cipango (Japón) en tanto es la isla, prisión alucinada. El poema titulado "Cipango" tiene una mención explí- 


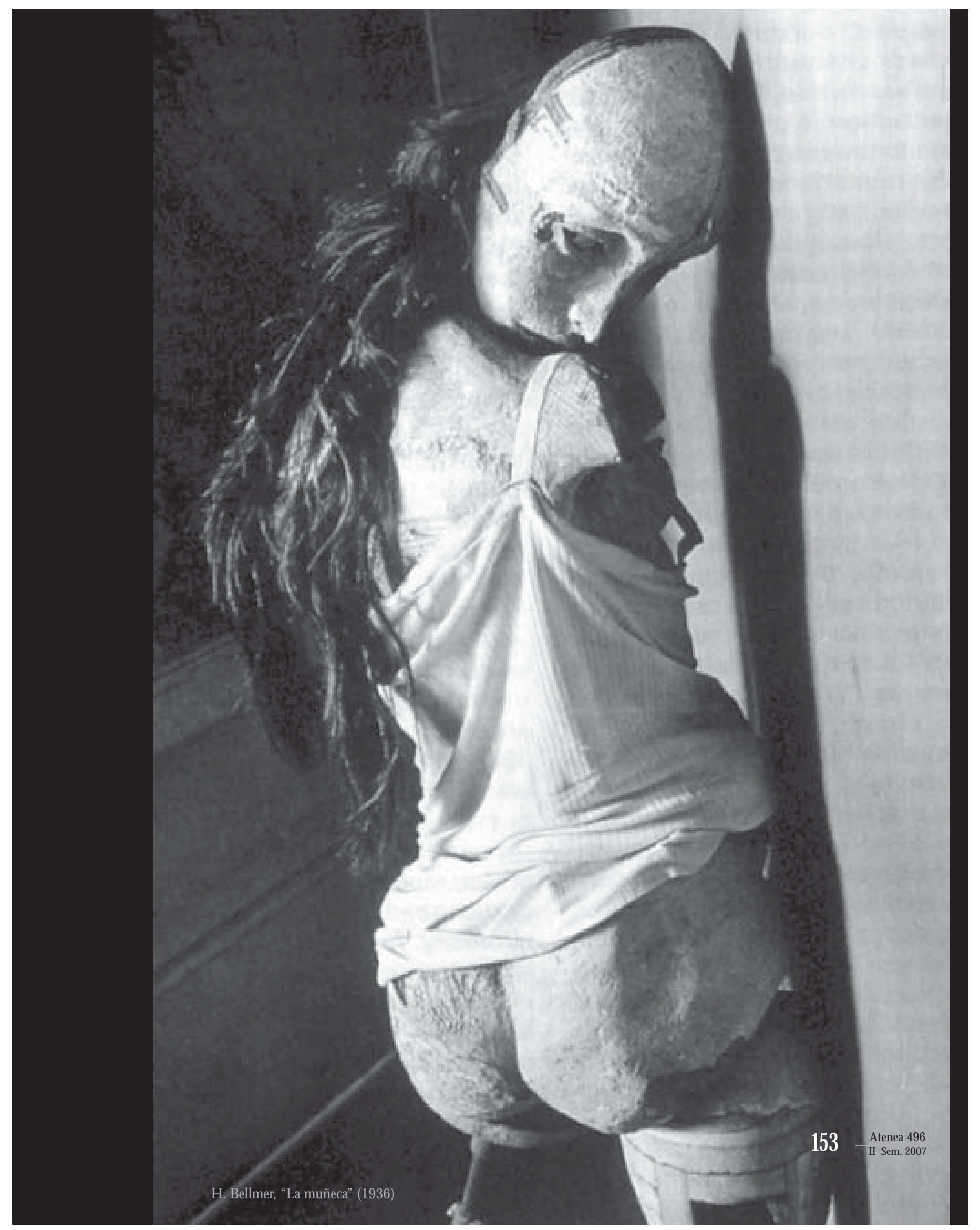




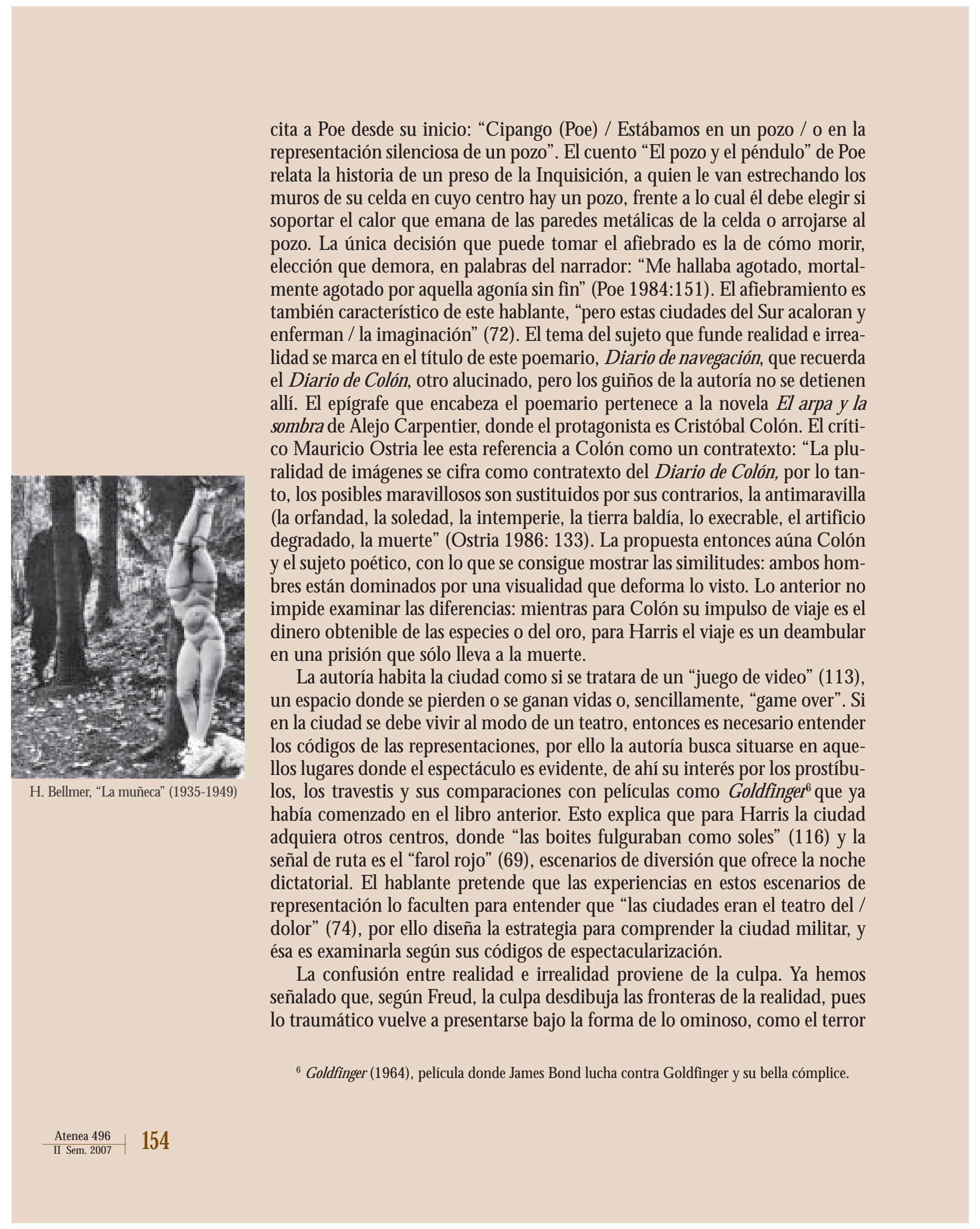


que experimenta el sujeto al reconocer en el inconsciente, pero desconocer en el consciente, la situación del shock. Los títulos de una serie de poemas hablan de la relación entre culpa y alucinación: " $M$ ar de los reflejos", "M ar de la culpa" y "Una indagación sobre esa pervertida manera de ver las cosas". El shock sería la experiencia del sujeto frente a las "bolsas de polietileno" (71) que remiten a la forma en que se envolvían y desechaban los cuerpos fusilados por la dictadura. La culpa está enfatizada por el hecho que el sujeto poético sería un traidor, alguien que cambió de posición después de los atropellos sufridos: "M e pararon al frente, me dijeron / habla / y hablé / M e pararon al frente, me dijeron / desnúdate / y me desnudé / M e pararon al frente, me dijeron / órlate / y me incrusté oropel, rubí, esmeraldas, pedrerías / oro falso / en el cuero. (A plausos) (83). H arris poetiza el capitalismo como una expansión de la esce na de tortura y a la vez caracteriza el consumo como una actitud aplaudida, legitimada. El hablante trata de justificar su travestismo ideológico: "a mí me acusaron / porque me había travestido para sepultarte, / porquemehabía ornado, incrustado oropel, / pedrerías, oro falso / en el cuerpo" (107). La aliteración del fonema " 0 " produce una completitud en el hablante que vuel ve reprochable su acción, no puede justificar su adopción por el oro con la necesidad de sepultar los cuerpos.

La confusión realidad/irrealidad se materializa espacialmente en la dicotomía entre baldío/brillo. El baldío es anunciado por la voz en off de quien veel peladero tras el espectáculo y advierte sobre el teatro de representaciones al visitante, "no toques lo que late porque desaparecerá al punto / del tacto / dijo una voz / cada cosa relumbra con el brillo / que sueña tu ojo" (67). El brillo está dado por la "música el ectrónica", los "cines" (67) y otros medios que fabrican la realidad, pero que a la vez ahogan la ciudad, impidiéndole el movimiento de "sístoles / diástoles" (68), dificultándole respirar y alcanzar la vida fuera dela representación. Sin duda, este tópico dela ciudad moderna, caracterizado por lo artificial, tiene un antecedenteen el N eruda de "Walking around" (1982), donde los "cines", "las sastrerías", "Ios jardines", "los ascensores" y otra serie de espacios urbanos definen la manicure citadina y el ahogo del sujeto, pero también hay distancia entre $\mathrm{H}$ arris y $\mathrm{N}$ eruda, pues en Diario de navegación lo artificial alcanza un grado de espectralidad que no está presente en $N$ eruda. Para la construcción del baldío habría que agregar además las políticas de erradicación. La nueva ciudad requiere de cambios, "el éxodo de las putas de O rompello / por edicto municipal / a Prat" (75), estas alteraciones son vigiladas por helicópteros y reflectores, donde los medios de la vigilancia se confunden con recursos de la espectacularización. Por ello, la entrada total de la socie dad del espectáculo y el brillo coincide con la dictadura en este libro.

La violencia que elimina o segrega sujetos es presentada en este poemario como un modo transhistórico, puesto queel sujeto iguala su rol en la dictadura con su participación en los hechos de fuerza acaecidos en los tiempos de fun-

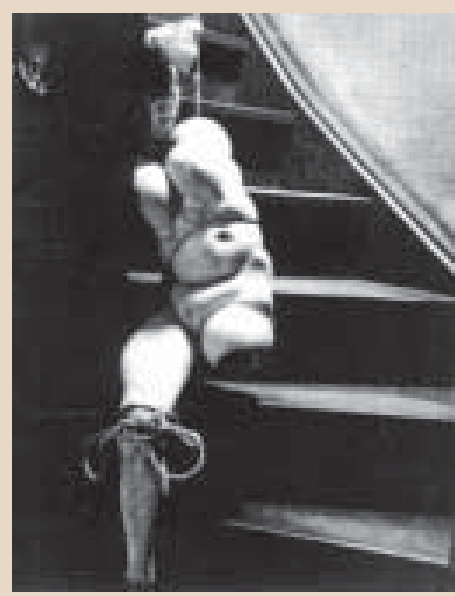

H. Bellmer, "La muñeca" 
dación de ciudades, el hablante es uno más de los viajeros colonizadores: "N os abríamos camino machete en mano, / tajando culos, / destasando tetas / talando araucarias" (77). D eesta manera, $\mathrm{H}$ arris iguala el sujeto dictatorial al sujeto colonizador, ambos convierten la ciudad en un baldío mediante sus políticas de exterminio decuerpos y asolamiento del medio ambiente. $\mathrm{H}$ arris, al decir la urbe contemporánea con el lenguaje de los primeros descubridores, recupera la extrañeza que la ciudad precolombina causó en el español, piénsese, por ejemplo, en el deslumbramiento anteTechnochtitlán, sólo que ahora no es asombro ante la magnificencia, sino ante el baldío. El peladero no son los barrios acomodados de la dictadura en la ciudad penquista: el barrio Universitario, el sector de Lonco o Villuco, sino los lugares populares: O rompello, el cerro La C ruz, la plaza I sabel LaC atólica y la población Libertad. Estos referentes muestran el deterioro de la ciudad latinoamericana, ya que, si antes la extrañeza se experimentó frente a la plenitud, ahora es ante la ausencia de vida, el paso del tiempo ha marcado la ruina en este lado del continente.

En el poemario se asocia la utopía del oro a la producción de la condición de fantasma; los espacios quedan espectral es cuando han sido construidos bajo la utopía que propone el capitalismo. En el verso "fantasmas como pueblo minero de California" (73), la comparación realza el efecto del dinero sobre estas ciudades, son espacios creados a partir de sujetos que llegan buscando el oro de esas tierras. Varios actos se igual an en estegesto: los españoles del descubrimiento, los lavadores de oro del siglo XIX con la dictadura instauradora de un sistema económico neoliberal. Estas nuevas ciudades creadas por interés económico son "como faro / como fuego fatuo" (73), es decir, entregan una luz falsa, una iluminación sólo de escenario, ya no existe la luz ilustrada. Incluso la aliteración de "f" reproduce ese fuego que no prende, el dinero sólo crea falsas ciudades. El fin de la ilustración es también el término de la participación pública, "M e cosieron la boca y los ojos / me inocularon Coca-Cola por las venas / todo transcurre en una película mexicana / what is your name me preguntó alguien" (85). H arris asocia la llegada del mundo globalizado y la caída de los grandes relatos a la dictadura: el imbunche chileno lo generó el autoritarismo.

Los iniciales rasgos posmodernos de la escritura se observan también en la conciencia de la espectacularización bajo la cual $\mathrm{H}$ arris vive la ciudad, pues ve el lenguaje con que se crea lo artificial al establecer una diferencia entre lo percibido y lo que efectivamente acontece. Lo comunicado por los medios es el brillo del dinero, pero lo que acontecees el baldío; a nivel de matriz esto puede leerse como: mientras el discurso del gobierno se centraba en la estabilidad económica, lo que acontecía era la pobreza. D e hecho, el libro se cierra mostrando esa diferencia: "esos resplandores que no son nada y nos deslumbran / los días de lluvia / en esta ciudad que brillaba como el mar, / pero que era un baldío" 
(117). La ciudad entendida como lugar de representación del espectáculo ya no se rige por la racionalidad del siglo de las luces, sino por las luces de los medios de comunicación, de ahí que H arris se permita esta ironía, "una lacerada procesión como esta en pleno Siglo de las Luces" (76). La designación "Siglo de las L uces" es empleada ahora para la era del espectáculo, u otra forma de leerlo sería afirmar que la máxima muestra de la razón técnica es el espectáculo $y$, por tanto, que fue la dictadura quien nos trajo el simulacro.

\section{CON CLUSIONES: EL NUEVO SIGLO DE LAS LUCES}

Tomás H arris poetiza una ciudad dominada por el simulacro posmoderno, haciendo coincidir la dictadura militar con la nueva urbe de las luces, la ciudad espectáculo, y dejando lejos los territorios construidos según el paradigma de la letra, propio de la modernidad. Finalizada la ciudad ilustrada, el lugar del sujeto ha cambiado, ya no es fijo, sino móvil, posee una enrancia travesti, cuyo antecedente es explicado por G. D ebord: "El espectáculo que es la eliminación de límites entre el yo y el mundo a través de la destrucción del yo asediado por la presencia-ausencia del mundo, es igualmentela eliminación de límites entre lo verdadero y lo falso, mediante el rechazo de toda experiencia vivida bajo la presencia real de la falsedad asegurada por la organización de la apariencia" (1995: 219). Justamente, es bajo la afirmación de la falsedad que se produce la destrucción del yo unitario en el poemario.

La urbe transformada en un falso escenario ofrece como ciudadanía un teatro de representaciones ejecutado para un vigilante anónimo situado en un panóptico que está dispuesto a al umbrar, señalar y erradicar a cual quier sospechoso. Iluminado bajo el miedo, el hablante se convierte en la voz de los traidores, los que se llenaron de oropeles, aquellos que creyeron en el brillo de las nuevas cuentas de plástico. Sin embargo, su travestismo está lleno de culpa, producto de lo cual la ciudad se transforma en un espacio ominoso.

La visión ominosa le impide al hablante distinguir entre el simulacro de ciudad y lo real, a saber, el baldío que corresponde al espacio habitado por fantasmas, cuerpos de detenidos desaparecidos, torturados y erradicados contados falsamente por la historia oficial. El baldío, en el libro, no es sólo un tema de la dictadura, sino una práctica que se inicia con la conquista española y sus políticas de erradicación. Por ello, el hablante que vive cautivo funde su habitar en Concepción, con Argel, Tebas, Cipango o C athay, remitiendo a las ciudades imaginadas y apestadas de la literatura o mejor dicho, igualando el sujeto dictatorial al colonizador y al sujeto posmoderno, en tanto todos siguen produciendo ese baldío del cual nunca hemos salido. 


\section{REFERENCIAS}

Bolaño, R. 1996. Estrella distante. Barcelona: Anagrama.

D ebord, G . 1995. La sociedad del espectáculo. Buenos Aires: La M arca.

Eliot, T.S. 1989. "La tierra baldía". Poeśas reunidas (1909-1962). M adrid: Alianza, pp. 77-87.

Eltit, D . 1983. Lumpérica. Santiago de Chile: Ediciones del O rnitorrinco.

Foucault, M . 1995. Vigilar y castigar. M éxico: Siglo XXI, pp. 199-230.

Freud, S. 1967. "Lo siniestro". O bras completas. Tomo VII. M adrid: Biblioteca Nueva. pp. 2483-2507.

Galindo, 0 . 2005. "N eomanierismo, minimalismo y neobarroco en la poesía chilena contemporánea". Estudi osfilológi cos 40. U niversidad Austral de C hile, sept., pp. 79-94.

H ahn, O . 1996. "C astillo dáteme date". Antología virtual. Santiago de Chile: FCE, p. 181.

H arris, T. 1996. "Zonas de peligro", "La forma de los muros", "D iario de navegación". Cipango. Santiago de Chile: FCE, pp. 25-118.

Lemebel, P. 1998. "K aren Eitel: La cosmética de la tortura, por canal 7 y para todo espectador". D e perlas y cicatrices. Santiago de Chile: Lom, pp. 90-92.

N eruda, P. 1982. "Walking around". Residencia en la Tierra. Argentina: O rbis.

N ómez, N . 1998. "Las crónicas maravillosas". El M ercurio. Santiago, 14, junio, p. E10.

O stria, M. 1986. "Primeros títulos de Cuadernos Sur: C astellano Girón, Tomás H arris, Andrés Gallardo". Extremos 2. Julio-diciembre, pp. 131-135.

----- . 1997. "Tomás H arrisy Juan Pablo Riveros: Conjuros y revelaciones". Atenea 476, pp. 109-117.

Poe, E. 1984. "El gato negro", "El pozo y el péndulo". N arraciones extraordinarias. Santiago de C hile: Ercilla.

Rastier, F. 1976. "Sistemática de las isotopías". En Geimas, A.J. (Comp.) Ensayos de semiótica poética. Barcelona: Planeta, pp. 107-140.

Riffaterre, M . 1978. Semiotics of Poetry. London: Indiana U niversity Press.

Silva, A. 2000. Imaginarios urbanos. Colombia: Tercer M undo Editores.

U rdanibia, I. 1990. "Lo narrativo en la posmodernidad". En torno a la posmodernidad. Barcelona: Anthropos, pp. 41-77.

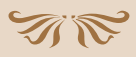

